\title{
The Construction Path and Mode of Public Tourism Information Service System Based on the Perspective of Smart City
}

\author{
Hongyan Ma (iD) ${ }^{1,2}$ \\ ${ }^{1}$ School of Humanities and Social Sciences, Xi'an Jiaotong University, Xi'an, Shaanxi Province 710049, China \\ ${ }^{2}$ School of Business, Xi'an Fanyi University, Xi'an, Shaanxi Province 710105, China \\ Correspondence should be addressed to Hongyan Ma; maria78@stu.xjtu.edu.cn
}

Received 30 September 2020; Revised 26 October 2020; Accepted 5 November 2020; Published 23 November 2020

Academic Editor: Wei Wang

Copyright $\odot 2020$ Hongyan Ma. This is an open access article distributed under the Creative Commons Attribution License, which permits unrestricted use, distribution, and reproduction in any medium, provided the original work is properly cited.

Under the framework of smart city, starting from the demand for urban public tourism information services, drawing on the new public service theory, customer perceived value theory, and basic information service theory, combined with previous research results, using literature analysis, questionnaire survey, and other methods, and starting from the carrier level of the public tourism information service system, this study analyzed the public tourism information services in detail. This study combed the current status quo and problems of the public tourism information service system for qualitative analysis and summed up some common shortcomings and deficiencies. Along with the results of the questionnaire, this paper analyzed the existing problems in the current public tourism information service system and identified the demands of tourists for public tourism information services. Based on this, the research puts forward the idea of constructing the public tourism information service system under the background of smart city, including the system framework, characteristics, service media and mode, operation mode, management mechanism, and other aspects. The study concluded that there is a need to construct theoretical and research models of the impact of public tourism services on the quality of destination from the perspective of smart city, to use the structural equation model for quantitative analysis, to verify the model hypothesis, and to consider that public tourism services have a significant positive impact on the behavioral and psychological responses of tourists. On the basis of combing the literature and starting from the overall situation, this study puts forward a systematic integration idea, which is of theoretical significance.

\section{Introduction}

The rapid development of information technology has laid an important material foundation for economic and social development, made processing and dissemination of information more convenient, made the media more diversified, changed the traditional service model, extended the industrial chain, and stimulated some new industries [1]. Thus, information resources have increasingly become an important factor of production, integrating with other industries. Tourism industry is one of the information-intensive industries [2]. The comprehensiveness and nonstorability of tourism products make informatization important, especially for tourism enterprises. Since the 1980s, information technology has been applied to business operations of China's tourism enterprises. After the rise of a large number of travel e-commerce sites, the independence of the Tourism Information Center and the National Tourism Administration "Golden Travel" is represented by "Ctrip Travel Network." The implementation of the "project" has laid to a solid foundation for China's tourism informatization construction [3].

The development of informatization has opened up a new development path for tourism. First, the promotion of tourism through online marketing is different from the traditional passive model that solely relies on travel agencies and word-of-mouth. It actively promotes tourism resources by providing information to every potential tourist who needs relevant information through the Internet and expands the popularity of tourism resources; second, the construction of tourism informatization enhances the reception capacity of tourist destinations and increases the 
satisfaction of tourists; then, a large number of tourism e-commerce sites have emerged in the construction of tourism informatization, seize the gaps in market demand, develop business management models, and enrich the tourism market. In addition, tourism informatization also plays an important role in protecting tourism resources, facilitating tourism services, protecting the rights and interests of tourists, and promoting the development of tourism products. It has become an important way for the transformation and upgrading of the tourism industry [4].

In the context of the rapid advancement of information technology and the boom of smart city construction, this study combs the status quo and problems of public tourism information service system, analyzes and evaluates the demand of tourists for public tourism information services, and combines the concepts and practices of smart city construction [5]. This study also provides ideas for constructing a public tourism information service system for smart cities, provides new directions for the transformation and upgrading of tourist cities, and lists some domestic cities as typical cases. It also analyzes their construction practices in the public tourism information service system in the process of smart city construction and identifies deficiencies and provides suggestions for countermeasures [6]. It provides important theoretical exploration and practical guidance value. The innovation of this research lies in (1) putting the tourists' demand perspective on the dominant position of the public tourism information service system. The public tourism information service system has public attributes, and general research focuses on the supply subject and supply mechanism. Less attention has been paid to this demand, which has caused repeated construction of the public tourism information service system and waste of resources. On the other hand, it has also lowered the satisfaction of tourists, especially individual tourists, which has affected the development of the local tourism industry [7]. This research starts from the reality and needs to be reflected in the questionnaire and is based on the perspective of tourists. (2) The theoretical model and the research model of the impact of tourism public services on destination brand relationship quality are constructed. A total of 36 factors in three dimensions forming a rectangular factor relationship structure model in the actual work of the tourism industry, around its development scale, and exploring new paths and methods for future research are constructed.

\section{The Rise of Smart Cities and the Transformation of Tourist Cities}

As early as 1992, Singapore first proposed the construction of a smart island, focusing on enhancing the city's information technology foundation [8]. In 2008, Industrial BM Company proposed the concept of "smart earth," thinking that "the world is becoming smaller, flatter, and smarter." Thus, the concept of "smart city" has also evolved. "Smart city" is built on the basis of "digital city," along with the wisdom concept of contracting BM, using advanced information technology for convenience and to communicate and operate more efficiently, advocate economic health and reasonable sustainability, harmonious and safe, comfortable life, and intelligent information management technology [9].

As soon as the smart city was proposed, it quickly gained wide attention and recognition. The governments of the United States, Europe, Singapore, South Korea, Japan, Hong Kong, and Taiwan launched smart city construction [10]. For example, as early as 2006, "Garden City" Singapore launched a ten-year "Smart Country 2015" (iN2015) plan; in July 2009, the Japanese government proposed after "e-Japan" and " $u$ Japan" [11] the updated version of the national informatization strategy, the medium and long-term information technology development strategy "i-Japan (Smart Japan) Strategy 2015," and designated Yokohama City in Kanagawa Prefecture, Toyota City in Aichi Prefecture, Toyota City in Kyoto Prefecture, and Toyota City in Fukuoka Prefecture. Four districts in Kitakyushu City plan to pilot smart cities; in October 2009, the European Union announced a new energy research investment plan, which will invest 11 billion euros for the "smart city" project and develop low-carbon housing in 25-30 cities and transportation [12].

2.1. The Construction of Smart City. The construction of smart cities in China presents four distinctive characteristics: first, the development of smart cities is highly valued and the enthusiasm for participation is increasing; hence, the number is increasing; second, the overall development among the cities is uneven, and the cities in the eastern coastal areas have a clear lead; third, the foundation of smart governance is solid, and the smart industry and infrastructure are steadily advancing. Finally, the government's service capabilities are more prominent, but the construction of typical applications and organizational systems lags significantly [13]. The rise of smart city construction around the world has brought a qualitative leap to the improvement of the city's overall informatization level. From the "smart city construction planning" and related documents issued by various cities, the basic construction of smart cities can be seen. The above all follow a certain model, combining the current status and long-term development planning of the city itself and constructing the three major systems of "bottom base layer-intermediate exchange layer-upper application layer" from the bottom up, which integrates citizens, tourists, enterprises, and governments in the city. Changing the traditional and backward operation and service modes of various roles, the intelligentization of life, production, and management is realized. The basic architecture of a smart city is shown in Figure 1.

With the transformation of China's economic development mode and the tourism industry, especially the increasing personalization and diversified needs of tourists, China's outstanding tourism cities have shown serious shortages in the reception capacity of individual tourists; at the same time, in the process of urbanization, problems such as environmental pollution, waste of resources, and population expansion have also spurred the transformation of China's outstanding tourism cities in search of new development methods. 


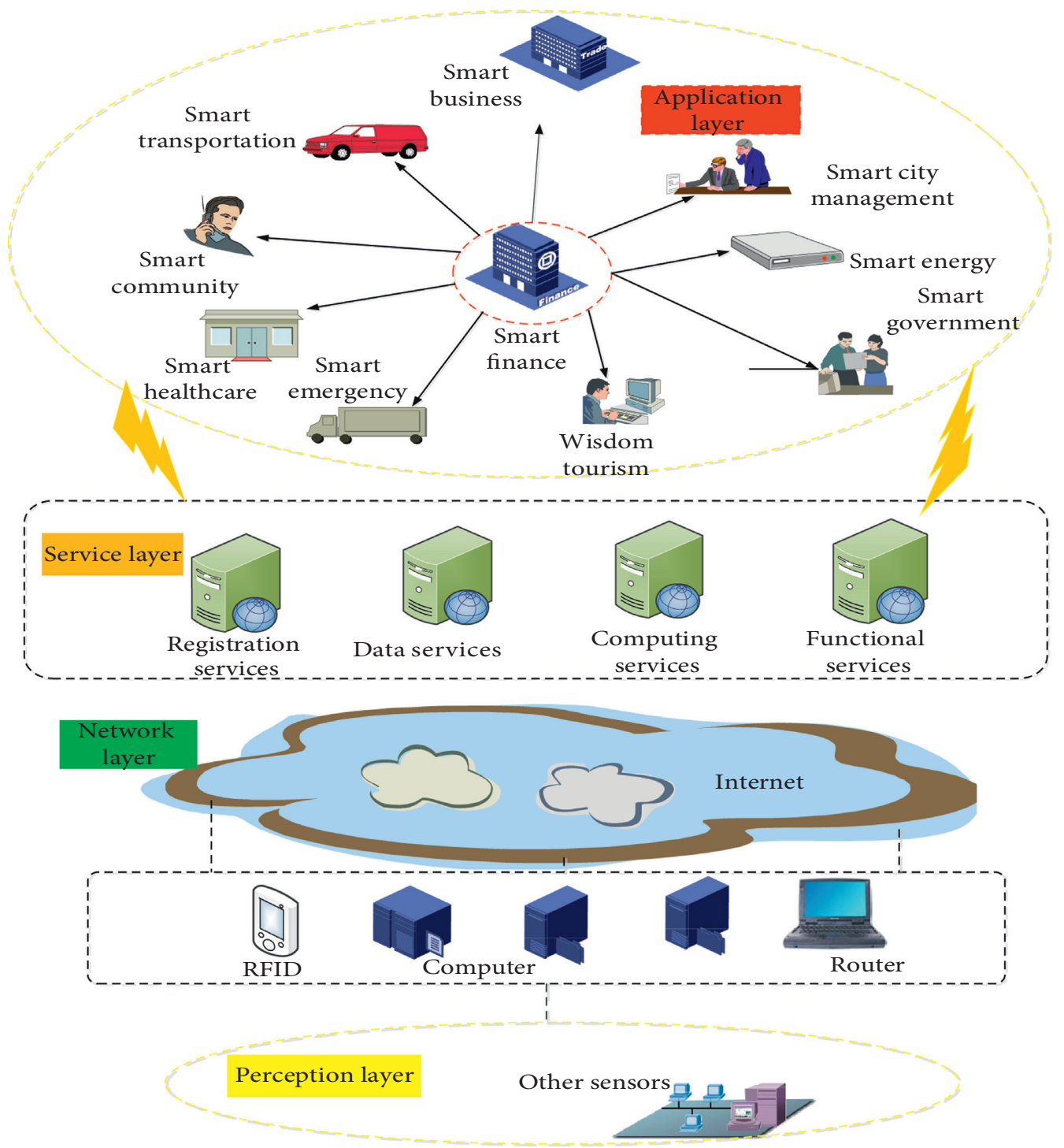

Figure 1: Basic architecture of a smart city.

The purpose of the transformation of China's outstanding tourism cities is to further optimize the urban tourism environment and improve urban tourism functions and the level of urban tourism management and service quality. But, its essence is to promote urban construction by expanding tourism consumption demand and to improve the city's opening degree, civilization quality, and international level [14]. In order to pursue transformation and achieve sustainable development, tourism cities have also been actively explored. Development paths such as ecologicalization, cultural creativity, low-carbon type, and informatization have become alternative directions and breakthroughs in the transformation of many tourist cities. The proposal of smart city provides a new path for the transformation and upgrading of tourist cities.

Smart transformation is in line with the general trend of tourism informatization development and is a concentrated expression of the integrated development of tourism and information technology industries. With the help of intelligent concepts and means, the conditions and support that the tourism industry of an excellent tourist city depends on can be comprehensively and systematically improved, thereby creating a good environment for the development of tourism.

2.2. Construction of Smart City Information Service Platform. In the construction of smart cities, in order to complete the storage and processing of massive data, it is necessary to build a processing platform that carries all applications. This platform has become the "smart city core platform." The smart city core information service platform promotes services such as triple play, office integration, intelligent interconnected buildings, digital media, city management, smart cards, collaboration, and centralized operation centers in areas such as residence, business, medical, education, and government affairs. Smart work spaces, smart transportation, smart buildings, smart energy, and smart society are connected together to form an overall smart system, as shown in Figure 2.

A cloud computing integrated platform with powerful data analysis capabilities is required to realize calculation, 


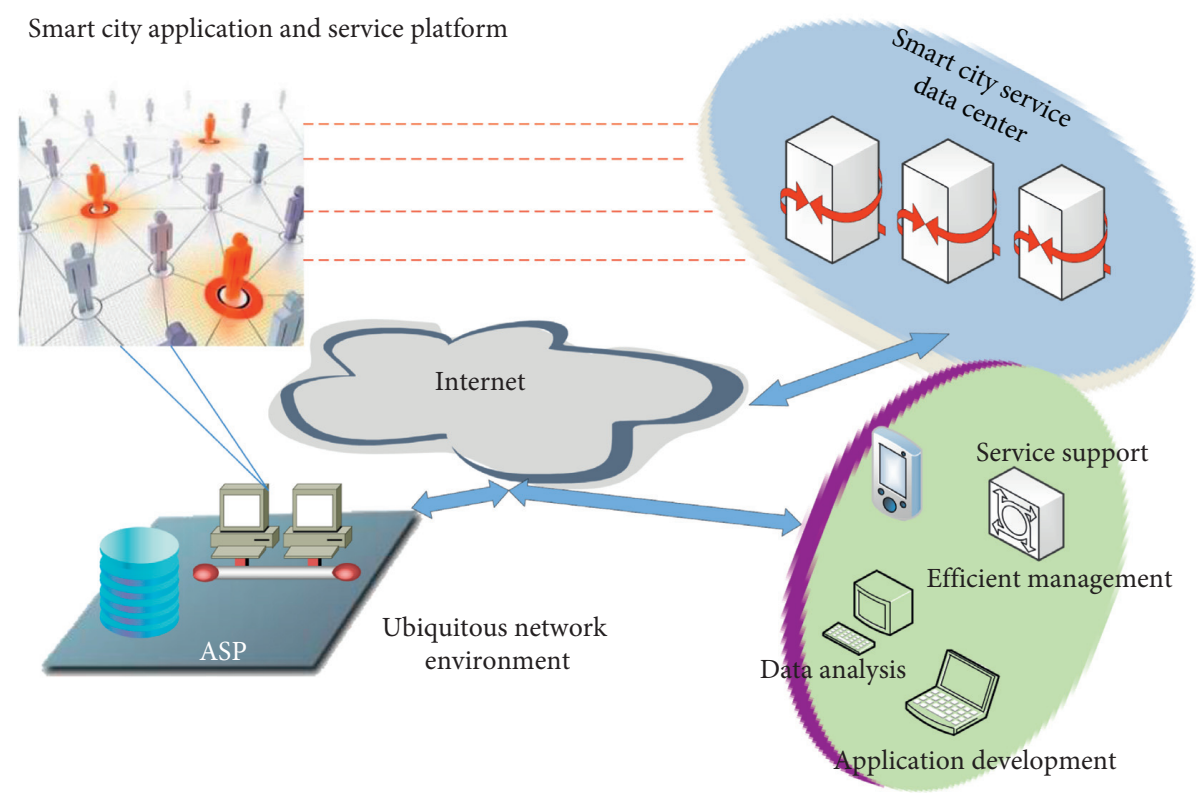

FIGURE 2: Smart city information service platform construction.

storage, analysis, processing, and decision-making of massive data. The "Smart City Core Platform" is different from ordinary industrial DCs and cloud computing centers and can achieve the following functions: providing running server hosting for the operation of all application systems and data space for the storage of all massive data. To meet the needs of city management, the core platform must be connected to the main administrative departments of the government; to meet the needs of citizens services, the core platform must be logically isolated from the Internet in order to meet the needs of information services. Various channels such as the Internet have established interaction mechanisms with citizens. Based on the Internet, using various information technologies, under the ubiquitous network environment, through the efficient management and application development of the city, the integrated application of the smart city service platform and smart city service data center is realized.

2.3. Construction Model Based on Internet of Things. As an application of the Internet, the Internet of Things is regarded as an important symbol of a "smart city." The country has proposed the Internet of Things strategy. After more than two years of promotion and development, the Internet of Things is no longer an abstract concept. The government and enterprises have gradually become more rational and clear in understanding the Internet of Things and have accumulated some construction experience. The core of the smart city is the construction of the Internet of Things system, so the smart city information service platform is divided into three levels: "perception layer," "network layer," and "application layer." Among them, the "perception layer" is to assemble sensors to real objects such as power grids, automobiles, buildings, household appliances, and water supply systems to a certain degree so as to achieve the connection of objects; the "network layer" is connected to wireless networks through interfaces and operates [15]. Through the integration of the city's unified network with telecommunications networks, radio grids, and the Internet, the city's unified network's basic environment and effective information transmission service highway are provided to the smart city public platform and various business application systems. The "network layer" is divided into "nearby," "transmission," and "remote transmission," which has two sublevels; the application layer is an application service system built on the smart city public platform, connecting the three major application sources of government, enterprises, and the public and providing them with a livable urban environment, security prevention and control, application services in areas such as life security, public services, and industrial optimization. The smart city construction model based on the Internet of Things is shown in Figure 3.

The industrialization of the Internet of Things and the development of R\&D applications are accelerating, speeding up the realization of real-time control and precise management of the world of the Internet of Things, and its ability to support economic operations and carry social public services is further improved and expanded. Through intelligent information equipment, efficient integration, interconnected ubiquitous networks, education, medical care, social management services, entertainment, socializing, etc., the necessity of life from "things" to "people" is as the center, from one-way diffusion shifts to the direction of participation and interaction. A new lifestyle with a wider range, a smarter, and a better experience gives people fingertips.

\section{Analysis of the Demand Survey Results of Public Tourism Information Service System}

The public tourism information services must rely on certain carriers to realize its service function, and its service efficiency is often reflected by the service level of these carriers in reality [15]. The carriers of public tourism information 


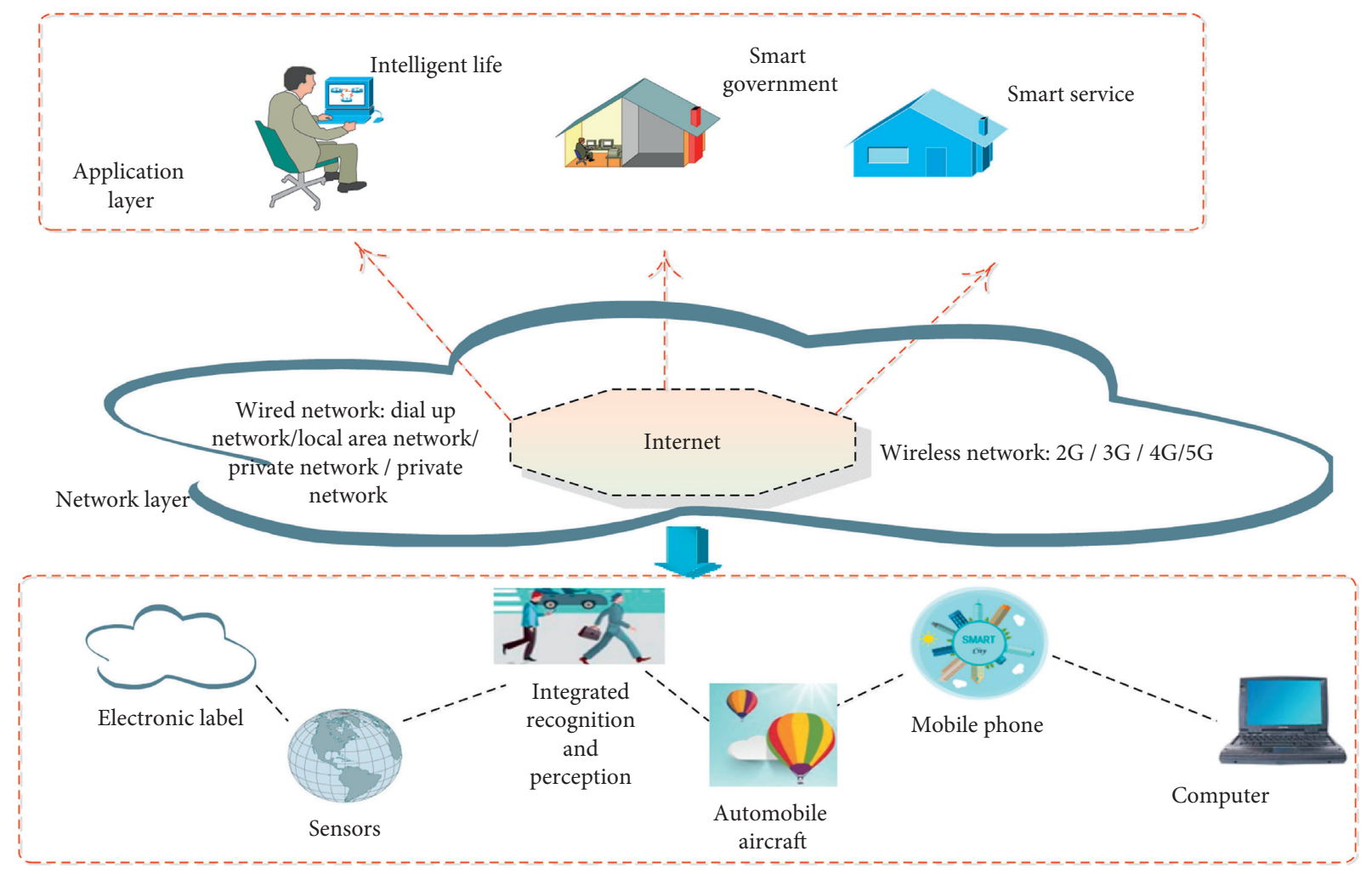

Figure 3: IoT-based construction model.

services generally include website (official website group of government part of tourism destination and public service information of commercial tourism website), tourism distribution center (naturally formed tourism distribution center and constructed tourism distribution center), the tourism consulting service site (the free consulting site set by tourism enterprises and the consulting site set by the Tourism Management Department), and the tourism call center. Reflecting the basic situation of the number, function, and intelligence of public tourism information service carriers, we can see the basic level and existing problems of public tourism information services [16].

3.1. Analysis of Tourism Information Demand. The demand for public tourism information services is high, accounting for $73.42 \%$, but there is also information demand for tourism, accounting for $26.58 \%$, nearly a quarter (Figure 4(a)). Therefore, information services in the process of tourism activities are also necessary.

Among the respondents, food, accommodation, shopping, bus routes, tourist attractions, language, and folk customs are still the main contents corresponding to the six elements of traditional tourism, such as food, accommodation, travel, shopping, and entertainment. However, $71.34 \%$ accounted for environmental and meteorological information (Figure 4(b)). It also becomes an important concern. However, the popularity of information content is very high, accounting for $55.25 \%$. Only $13.24 \%$ of the respondents preferred to customize the content of public tourism information services, and the choice between the two accounts for $32.51 \%$ (Figure 5(a)). On the one hand, it is consistent with the public attribute of the public tourism information services, and it also shows that tourists still have a certain tendency towards customized services and do not want to fully popularize them.

3.2. Analysis of the Ways and Forms of Tourists' Demand for Tourism Information Services. Among the existing public tourism information service channels, tourists have the strongest perception of the importance of the Internet, reaching $10.5 \%$. Mobile phones rank fourth, while the tourism service hotline ranks last (Figure 5(b)). It can be seen that tourists have a strong demand for tourism information on the Internet and mobile phones, but although the tourism service hotline has been opened nationwide, it does not get the attention of tourists. In contrast, tourists like the form of network interaction the most, followed by onsite consultation and telephone consultation (Figure 6). In the survey, $88.5 \%$ of the respondents have such demands, so the demands in this regard cannot be ignored.

3.3. Reliability Test and Data Purification. After ensuring the validity, trend, and distribution of sample data meet the requirements, this study also needs to test the reliability and validity of the scale used in empirical analysis. In the reliability test of the scale of the impact of public tourism services on the quality of destination brand relationship, this study uses the widely used corrected-item total correlation (CITC) index and internal consistency Cronbach's alpha coefficient to analyze. 


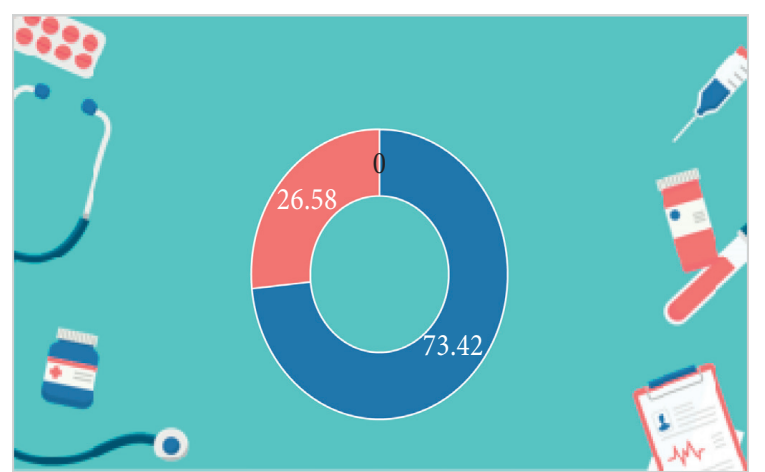

- Before tourism

- Tourism end After tourism

(a)

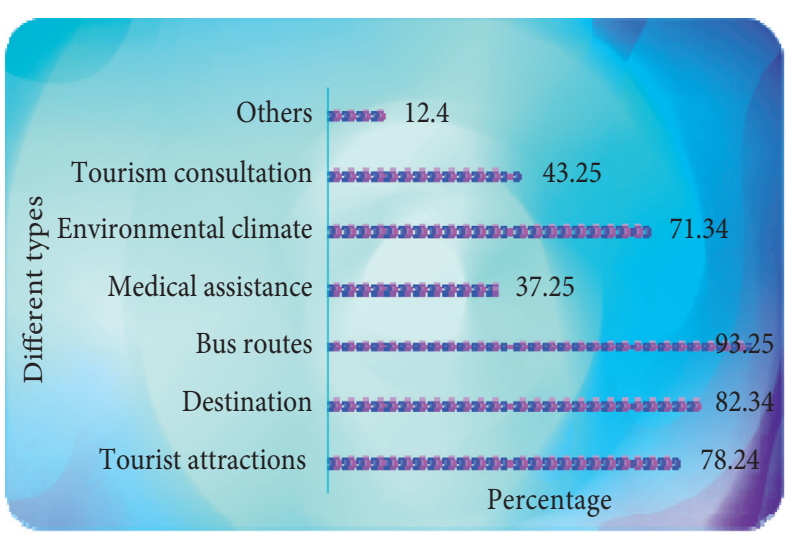

(b)

FIgURE 4: (a) Distribution stage of tourism information demand. (b) Content analysis of tourism information demand.

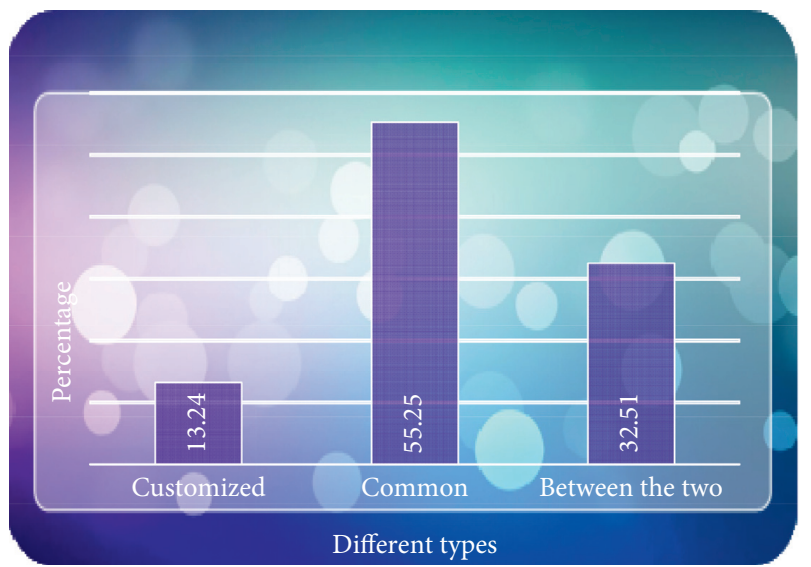

(a)

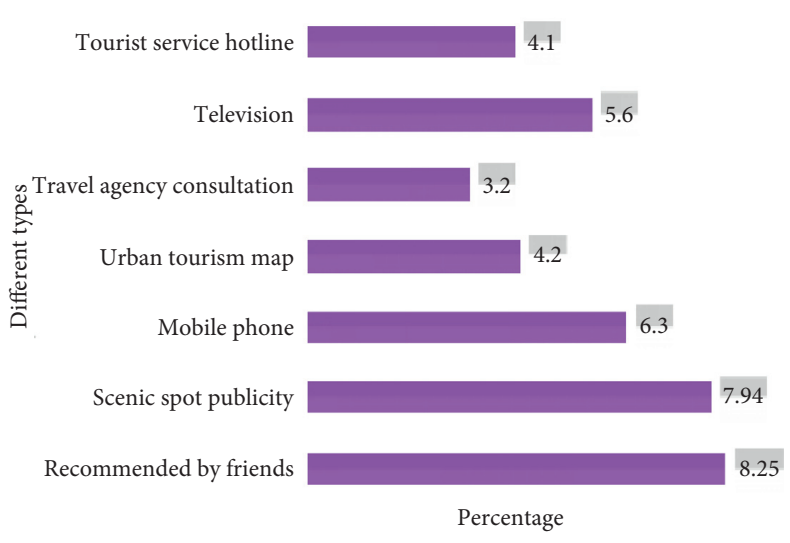

(b)

FIgURE 5: (a) Universality analysis of tourists' demand for tourism information services and (b) ranking of importance of tourism information service channels.

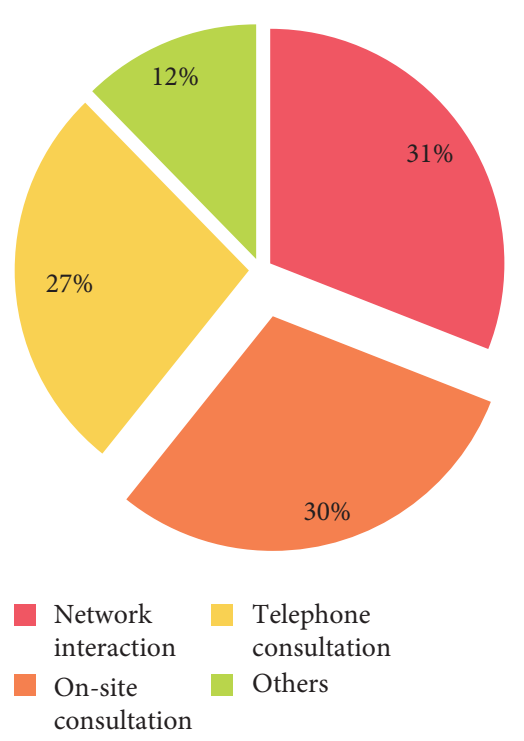

(a)

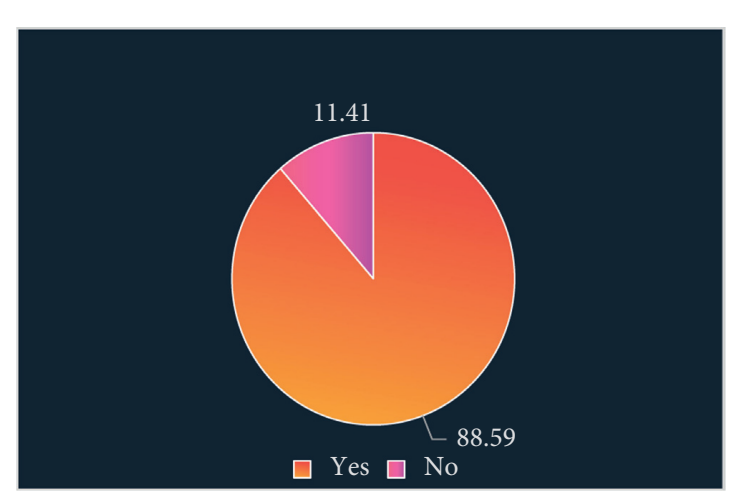

(b)

FiguRE 6: (a) Ranking of tourists' preference for consulting services and (b) investigation of tourists' mood sharing needs. 
In this study, after reliability analysis, the main standards used for data purification are as follows: corrected-item total correlation index (CITC) to purify the data and each item. When the strict CITC standard $a$ is less than 0.5 , the measurement item should be deleted, but it is also a relatively loose standard. For example, Lu Wendai considered that if the CITC index of the item is greater than 0.3 , and the line with the requirements need further analysis. In this study, the scale of CITC is selected as 0.5 , the test standard of Cronbach's $\alpha$ coefficient [17]. Bashynska considers that the coefficient above 0.6 is acceptable, while others consider that the coefficient above 0.7 is the minimum acceptable value. In this study, the strict coefficient is more than 0.7 as the standard [18].

Using the sample data collected in this survey, SPSS 20.0 software was used in this study. Firstly, the CITC index of each item should be greater than 0.5; otherwise, the item should be deleted. In Table 1, except the CITC index of S01 (0.518), all of them are greater than 0.5 , and the deletion of S01 here will lead to unsuitable analysis in the structural equation model, and the CITC index of S01 is also too close to 0.5 , so we reserve it here [19].

Secondly, Cronbach's $a$ index of the whole scale is calculated. The result shows that Cronbach's $\alpha$ index is 0.938 , and the $a$ index after removing a certain question item will not change significantly. In addition, Cronbach's $\alpha$ index of 12 factor variables in the scale was calculated.

It can be seen that Cronbach's $a$ index of the overall scale of the impact of each factor of public tourism services on each factor of destination brand relationship quality and the scale of each factor is above 0.700 .

\section{Construction of Public Tourism Information Service System Based on Smart Cities}

4.1. Factor Analysis. In SPSS 20.0, factor analysis was conducted again for reliability analysis and purified data. When the factor loading of the item is greater than 0.5 and the cumulative proportion of explanatory variance is greater than $50 \%$, it is up to the standard. According to the analysis of the previous chapter and the design of the questionnaire structure, all items are divided into three dimensions, four parts, and thirty-six items. Factor analysis is carried out on the public services of tourism, the behavioral response of tourists, the psychological response of tourists, and the quality of destination brand relationship. The factor loads of each item, Kaiser-Meyer-Olkin value, Bartlett's sphericity test (Butler's sphericity test), and Cronbach's $a$ index were observed.

4.1.1. Factor Analysis of Public Tourism Services. Firstly, we extract the main components. Secondly, the KMO test is carried out. Finally, Bartlett's sphericity test (Butler's sphericity test) was carried out. The testing results are shown in Table 2.

Among them, factor F1 represents the traffic service in public tourism services, and the factor load of the measurement items is A02 (0.956), A01 (0.924), and A03 (0.943), the KMO value is 0.765 , Bartlett's sphericity test (Butler's ball test) $P$ value is significant at 0.001 level, and the overall Cronbach's $\alpha$ index (see Table 1 ) is 0.938 . Factor F2 represents hotel service in public tourism services, and the factor load of measurement items is B02 (0.918), B01 (0.922), and B03 (0.873), the KMO value is 0.735 , Bartlett's sphericity test (Butler's ball type test) $P$ value is significant at 0.001 level, and the overall Cronbach's $\alpha$ index (see Table 1) is 0.889 . Factor $\mathrm{F} 3$ represents tourism service in public tourism services, and the factor load of measurement items is $\mathrm{C} 02$ (0.914), C01 (0.913), and C03 (0.872), the KMO value is 0.730 , Bartlett's sphericity test (Butler's test) $P$ value is significant at 0.001 level, and the overall Cronbach's $\alpha$ index (see Table 1) is 0.824 .

4.1.2. Response Factor Analysis of Tourists' Behavior. Firstly, we extract the main components. Secondly, the KMO test is carried out. Finally, Bartlett's sphericity test (Butler's sphericity test) was carried out. The results are shown in Table 3.

Among them, factor F4 represents the reliability factor in the tourists' behavior response, and the factor load of the measurement items is L02 (0.892), L01 (0.842), and L03 (0.823), the KMO value is 0.694 , Bartlett's sphericity test (Butler's ball test) $P$ value is significant at 0.001 level, and the overall Cronbach's $\alpha$ index (see Table 1 ) is 0.825 . Factor F5 represents the competency factor in the tourists' behavior response. The factor load of measurement items is M03 (0.917), M02 (0.846), and M01 (0.832), the KMO value is 0.661 , Bartlett's sphericity test (Butler's ball test) $P$ value is significant at 0.001 level, and the overall Cronbach's $\alpha$ index (see Table 1) is 0.827 . Factor F6 represents the communication factor in the tourists' behavior response. The factor load of measurement items is N02 (0.831), N01 (0.782), and N03 (0.742), the KMO value is 0.634 , Bartlett's sphericity test (Butler's ball test) $P$ value is significant at 0.001 level, and the overall Cronbach's $\alpha$ index (see Table 1 ) is 0.750 .

4.1.3. Analysis of Psychological Response Factors of Tourists. Firstly, we extract the main components. Secondly, the KMO test is carried out. Finally, Bartlett's sphericity test (Butler's sphericity test) was carried out. Table 4 shows the testing results.

Among them, factor F7 represents the safety factor in tourists' psychological response, and the factor load of measurement items is R02 (0.896), R01 (0.862), and R03 (0.840), the KMO value is 0.744 , Bartlett's globosity test (Butler's globosity test) $P$ value is significant at 0.001 level, and the overall Cronbach's $\alpha$ index (see Table 1) is 0.814 . Factor F8 represents the trust factor in tourists' psychological response, and the factor load of measurement items is S02 (0.890), S03 (0.783), and S01 (0.725), the KMO value is 0.592 , Bartlett's sphericity test (Butler's sphericity test) $P$ value of is significant at the level of 0.001 , and the overall Cronbach's $\alpha$ index (see Table 1 ) is 0.734 . Factor F9 represents the politeness factor in tourists' psychological response, and the factor load of the measurement items is T02 
TABLE 1: Reliability analysis.

\begin{tabular}{lcccc}
\hline Variables & Item & Total correlation corrected by item & Cronbach's $\alpha$ value after deleting the item & Cronbach's $\alpha$ \\
\hline Smart transportation & A01, A02, A03 & 0.882 & 0.930 & 0.881 \\
Smart hotel & B01, B02, B03 & 0.893 & 0.759 & 0.938 \\
Smart tourism & C01, C02, C03 & 0.793 & 0.768 & 0.889 \\
Reliability & L01, L02, L03 & 0.649 & 0.719 & 0.824 \\
Communication & M01, M02, M03 & 0.626 & 0.801 & 0.825 \\
Winning willfulness & N01, N02, N03 & 0.503 & 0.829 & 0.750 \\
Security & R01, R02, R03 & 0.742 & 0.817 & 0.814 \\
Trustworthiness & S01, S02, S03 & 0.518 & 0.734 \\
Politeness & T01, T02, T03 & 0.612 & & 0.792 \\
\hline
\end{tabular}

TABLE 2: Factor analysis of public tourism services.

\begin{tabular}{lccc}
\hline Number & The traffic at the destination is convenient and fast & F1 & F2 \\
\hline A01 & The process of purchasing this travel and transportation product is smooth & 0.924 & F3 \\
A02 & In this travel traffic, I feel the advantages of Internet plus & 0.943 & - \\
A03 & Destination hotel is clean and comfortable & - \\
B01 & The process of purchasing the hotel accommodation product is smooth & - & 0.918 \\
B02 & I feel the advantages of Internet plus in this trip accommodation & 0.922 \\
B03 & Destination quality is high and intelligent & - \\
C01 & The process of purchasing products for this tour is smooth & - \\
C02 & In this tour, I feel the advantages of Internet plus & - \\
C03 & & 0.973 \\
\hline
\end{tabular}

TABLE 3: Response factor analysis of tourists' behavior.

\begin{tabular}{|c|c|c|c|c|}
\hline Number & Item & F1 & $\mathrm{F} 2$ & F3 \\
\hline L01 & The commitment of the tourism product or service provider of the destination has fulfilled & 0.842 & & \\
\hline L02 & The tourism products or services I buy can complete consumption or experience & 0.894 & - & - \\
\hline L03 & The provider of tourism products or services at the destination is reliable & 0.823 & & \\
\hline M01 & When I have problems, I know whom to talk to and can communicate with & & 0.832 & \\
\hline $\mathrm{MO} 2$ & Internet and the social platform play a great role in my tourism communication & - & 0.846 & - \\
\hline M03 & No problem of smooth or improper communication in my whole tourism activity & & 0.917 & \\
\hline N01 & The scenic spot of the destination can provide corresponding products or services & & & 0.782 \\
\hline NO2 & The service personnel at the destination is competent for his/her work & - & - & 0.831 \\
\hline N03 & Internet plus or intelligent building of N03 destination can meet my needs & & & 0.742 \\
\hline
\end{tabular}

TABle 4: Psychological effects of tourists.

\begin{tabular}{|c|c|c|c|c|}
\hline Number & Item & F1 & $\mathrm{F} 2$ & F3 \\
\hline R01 & The social security and safety facilities at the destination are good & 0.862 & & \\
\hline R02 & I did not feel any threat or danger in this tour & 0.896 & - & - \\
\hline $\mathrm{R} 03$ & The travel products and services I buy are safe & 0.840 & & \\
\hline S01 & The provider of tourism products or services at the destination is reliable & & 0.725 & \\
\hline S02 & I am treated equally and honestly in tourism activities & - & 0.890 & - \\
\hline S03 & I did not encounter any dishonesty in this tour & & 0.783 & \\
\hline T01 & The tourism product or service provider of the destination is civilized and polite & & & 0.802 \\
\hline TO2 & I did not encounter any impolite or uncivilized events in this tour & - & - & 0.837 \\
\hline T03 & I feel that the civilization and politeness of the destination are very high & & & 0.792 \\
\hline
\end{tabular}

(0.837), T01 (0.802), and T03 (0.792) from large to small, the KMO value is 0.659 , Butler's ball test $P$ value is significant at 0.001 level, and the overall Cronbach's $\alpha$ index (see Table 1 ) is 0.792 .

The problems and shortcomings of the public tourism information service system are the factors that hinder the development of tourism industry into a "modern service industry more satisfactory to the people." The main reason lies in the inappropriate framework and mode of the transformation and upgrading of tourism services, the failure to fully consider the domestic environment and conditions, the failure to find a good foothold and entry point, and the lack of many ideas that are beneficial to practice [20]. For example, although the international experiential public tourism information service mode enhanced, international exchange activities were active. Some 


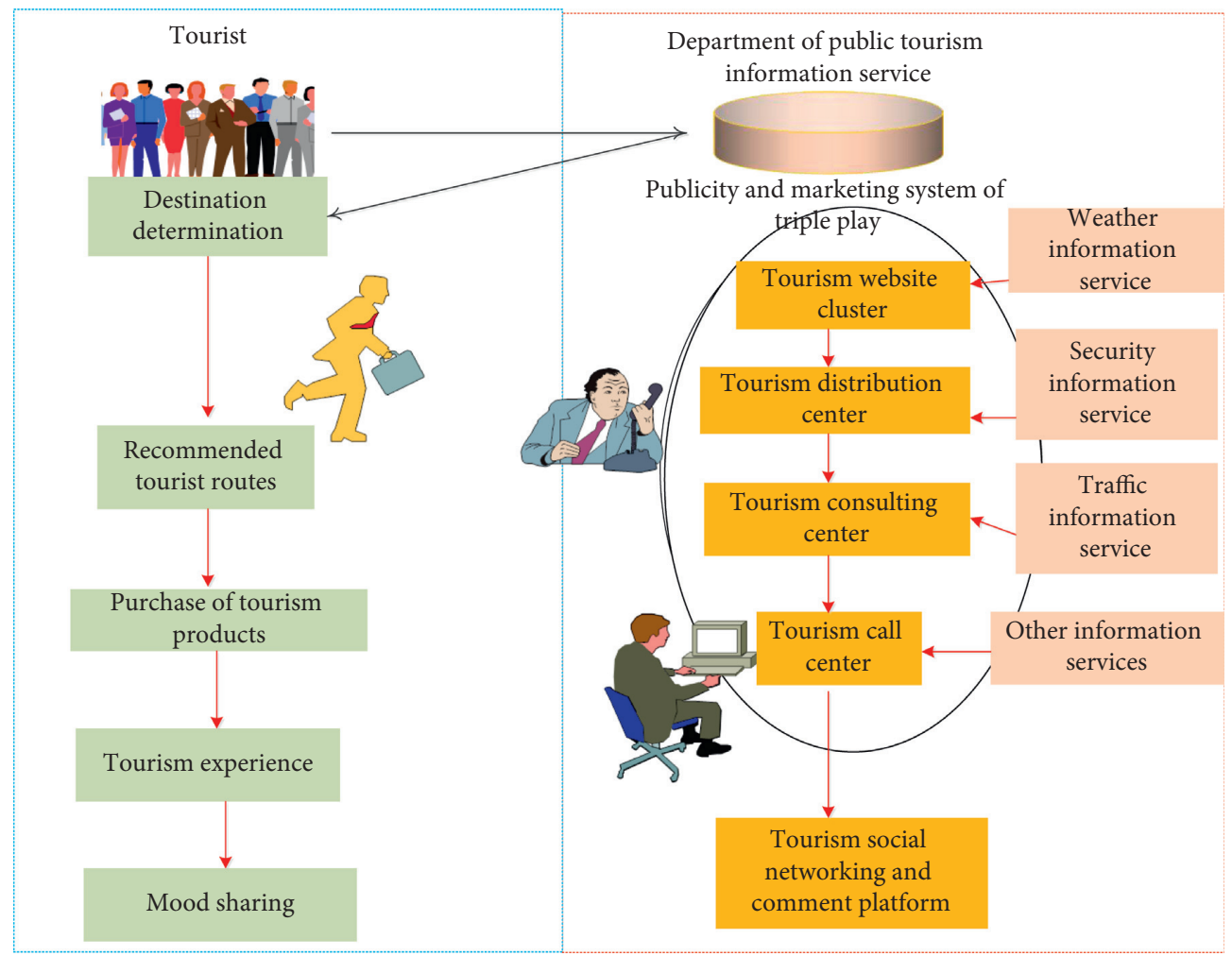

FIgURE 7: Public tourism information services for smart city.

tourist destinations learn a full range of foreign public tourism information service modes and means, which are applied to domestic construction, regardless of the environmental conditions of the region, resulting in the mode not applicable and not working. Therefore, the most important thing in the construction of the public tourism information service system is applicability, which is based on the existing basis and conditions.

\subsection{Construction of the Public Tourism Information Service} System for Smart City. On the basis of the system, platform, and operation management platform built for the construction of smart city, the improvement of the public tourism information service system is realized, the problems existing in the traditional public tourism information service system are changed, and the shortcomings are summed up. The public tourism information service system of face-toface smart city is more humanized in terms of overall construction and basic characteristics and service media and methods intellectualization.

The traditional public tourism information service system is based on the perspective of tourism supply, including four parts: tourism website cluster, tourism distribution center, tourism consulting service center (station), and tourism call center. Each part has several subsystems or divided into several forms. It is built, operated, and managed by each department independently, lacking information interoperability and cooperation. With the rapid development of smart city construction, smart ideas provide new directions and methods for urban management and services and gradually get wide recognition and support. Smart cities also provide system, platform, and operation management support for the transformation and upgrading of the public tourism information service system. Therefore, the construction of the public tourism information service system for smart city is of great practical significance and very feasible.

From the analysis of the statistical results, it shows that tourists' dissatisfaction with the public tourism information service is mainly concentrated in the aspects of incomplete content, poor timeliness of updating, poor interoperability, and single form; the demand for the quantity and quality of public tourism information can be summarized as the characteristics of desirability, timeliness, comprehensiveness, system, relevance, and accuracy. These characteristics need to change the tradition. The public tourism information service system of China has become a key target to improve the satisfaction of tourists and a key index to build a new service system.

4.3. Mode of the Public Tourism Information Service System for Smart City. With the rapid development of smart city construction, smart ideas provide new directions and methods for urban management and services and gradually get wide recognition and support. Smart cities also provide system, platform, and operation management support for the transformation and upgrading of the public tourism information service system. Therefore, the construction of the public tourism information service system for smart city is of great practical significance and very feasible. 
To build a public tourism information service system for smart city, with the help of the concept and construction foundation of smart city, starting with the improvement of the carrier of public tourism information services, improve the channels of public tourism information services, optimize the means of services, endow it with intelligent core, and cover the needs of the public tourism information service system reflected by the questionnaire. The public tourism information service system for smart city is shown in Figure 7.

\section{Conclusion}

This paper systematically analyzes and summarizes the problems and shortcomings of the existing public tourism information service system and, through the form of questionnaire, realizes the information demand characteristics of tourists, especially the individual tourists. Solving these problems in combination with the needs is the key to improving the public tourism information service system. To solve these problems and deficiencies, the proposal and construction of smart city is the key direction. With the consideration of the current situation, this paper analyzes the foundation platform of smart city for the construction of the public tourism information service system, mainly including the understanding foundation, physical foundation, and management foundation. On the basis of smart city, it is scientific and feasible to realize the construction of the public tourism information service system. This paper presents a systematic model, starting from the needs of tourists and aiming at the characteristics of tourists' demand for information before, during, and after tourism; the tourism supplier is extended to the whole society and tourism-related industrial departments. The government departments, as the main body of the service providers, realize the interconnection of various suppliers and information under the security mode and realize the intelligent communication under the stimulation of the city, and the innovation of service media, means, and management mode is constantly realized.

\section{Data Availability}

The data used to support the findings of this study are available from the corresponding author upon request.

\section{Conflicts of Interest}

The authors declare that they have no known conflicting financial interest or personal relationships that could have appeared to influence the work reported in this paper.

\section{Acknowledgments}

This work was supported by the major projects of the $\mathrm{Na}$ tional Social Science Fund in 2018: The history, current situation, and future of information philosophy (project no. 18zda027).

\section{References}

[1] Y. Li, C. Hu, C. Huang, and L. Duan, "The concept of smart tourism in the context of tourism information services," Tourism Management, vol. 58, pp. 293-300, 2017.

[2] J. Wang, C. Jiang, K. Zhang, T. Q. Quek, Y. Ren, and L. Hanzo, "Vehicular sensing networks in a smart city: principles, technologies and applications," IEEE Wireless Communications, vol. 25, no. 1, pp. 122-132, 2017.

[3] R. Díaz-Díaz, L. Muñoz, and D. Pérez-González, "Business model analysis of public services operating in the smart city ecosystem: the case of smart Santander," Future Generation Computer Systems, vol. 76, no. 6, pp. 198-214, 2017.

[4] V. A. Memos, K. E. Psannis, Y. Ishibashi, B.-G. Kim, and B. B. Gupta, "An efficient algorithm for media-based surveillance system (EAMSuS) in IoT smart city framework," Future Generation Computer Systems, vol. 83, no. 3, pp. 619-628, 2018.

[5] M. M. Rathore, A. Paul, W.-H. Hong, H. Seo, I. Awan, and S. Saeed, "Exploiting IoT and big data analytics: defining smart digital city using real-time urban data," Sustainable Cities and Society, vol. 40, no. 4, pp. 600-610, 2018.

[6] Y. Wu, W. Zhang, J. Shen, Z. Mo, and Y. Peng, "Smart city with Chinese characteristics against the background of big data: idea, action and risk," Journal of Cleaner Production, vol. 173, no. 3, pp. 60-66, 2018.

[7] H. Kim, L. Mokdad, and J. Ben-Othman, "Designing UAV surveillance frameworks for smart city and extensive ocean with differential perspectives," IEEE Communications Magazine, vol. 56, no. 4, pp. 98-104, 2018.

[8] M. Gohar, M. Muzammal, and A. Ur Rahman, "SMART TSS: defining transportation system behavior using big data analytics in smart cities," Sustainable Cities and Society, vol. 41, no. 1, pp. 114-119, 2018.

[9] P. G. V. Naranjo, Z. Pooranian, M. Shojafar, M. Conti, and R. Buyya, "FOCAN: a fog-supported smart city network architecture for management of applications in the internet of everything environments," Journal of Parallel and Distributed Computing, vol. 132, no. 2, pp. 274-283, 2019.

[10] N. Komninos, C. Kakderi, A. Panori, and P. Tsarchopoulos, "Smart city planning from an evolutionary perspective," Journal of Urban Technology, vol. 26, no. 2, pp. 3-20, 2019.

[11] K. Zhang, J. Ni, K. Yang, X. Liang, J. Ren, and X. S. Shen, "Security and privacy in smart city applications: challenges and solutions," IEEE Communications Magazine, vol. 55, no. 1, pp. 122-129, 2017.

[12] X. Li, P. S. W. Fong, S. Dai, and Y. Li, “Towards sustainable smart cities: an empirical comparative assessment and development pattern optimization in China," Journal of Cleaner Production, vol. 215, no. 5, pp. 730-743, 2019.

[13] Z. Khan, Z. Pervez, and A. G. Abbasi, "Towards a secure service provisioning framework in a smart city environment," Future Generation Computer Systems, vol. 77, no. 7, pp. 112-135, 2017.

[14] V. Della Corte, C. D’Andrea, I. Savastano, and P. Zamparelli, "Smart cities and destination management: impacts and opportunities for tourism competitiveness," European Journal of Tourism Research, vol. 1, no. 7, pp. 7-27, 2017.

[15] I. Lopez-Carreiro and A. Monzon, "Evaluating sustainability and innovation of mobility patterns in Spanish cities. analysis by size and urban typology," Sustainable Cities and Society, vol. 38, no. 8, pp. 684-696, 2018.

[16] D. Grimaldi and V. Fernandez, "The alignment of university curricula with the building of a smart city: a case study from 
Barcelona," Technological Forecasting and Social Change, vol. 123, no. 3, pp. 298-306, 2017.

[17] G. Viale Pereira, M. A. Cunha, T. J. Lampoltshammer, P. Parycek, and M. G. Testa, "Increasing collaboration and participation in smart city governance: a cross-case analysis of smart city initiatives," Information Technology for Development, vol. 23, no. 3, pp. 526-553, 2017.

[18] I. Bashynska and A. Dyskina, "The overview-analytical document of the international experience of building smart city," Business: Theory and Practice, vol. 1, no. 9, pp. 228-241, 2018.

[19] W. Ejaz, M. Naeem, A. Shahid, A. Anpalagan, and M. Jo, "Efficient energy management for the internet of things in smart cities," IEEE Communications Magazine, vol. 55, no. 1, pp. 84-91, 2017.

[20] V. Moustaka, A. Vakali, and L. G. Anthopoulos, "A systematic review for smart city data analytics," ACM Computing Surveys (CSUR), vol. 51, no. 5, pp. 1-41, 2018. 